\title{
Heart failure therapy based on interventricular mechanics and cardio-vascular communications
}

\author{
Dietmar Schranz ${ }^{1,2}$, Hakan Akintuerk ${ }^{1}$, Anoosh Esmaeili ${ }^{2}$, Heiner Latus ${ }^{3}$, Christian Apitz ${ }^{4}$ \\ ${ }^{1}$ Pediatric Heart Center, Justus-Liebig University, Giessen, Germany; ${ }^{2}$ Pediatric Cardiology, University Clinic Frankfurt, Frankfurt, Germany; \\ ${ }^{3}$ Pediatric Cardiology, German Heart Center, Munich, Germany; ${ }^{4}$ Pediatric Cardiology University Hospital Ulm, Ulm, Germany \\ Contributions: (I) Conception and design: D Schranz; (II) Administrative support: None; (III) Provision of study materials or patients: D Schranz; \\ (IV) Collection and assembly of data: None; (V) Data analysis and interpretation: None; (VI) Manuscript writing: All authors; (VII) Final approval of \\ manuscript: All authors. \\ Correspondence to: Dietmar Schranz. Pediatric Heart Center, Justus-Liebig University, Feulgenstrasse 12, 35385 Giessen, Germany. \\ Email: Dietmar.Schranz@paediat.med.uni-giessen.de.
}

\begin{abstract}
The heart should not be divided in right and left, whether in health nor in disease. However, the morphological and functional differences between the right and left ventricle should be known and the impact of the ventricle's position considered. Further, the parameters beyond heart rate, contractility, preand afterload guaranteeing a sufficient systemic cardiac output have to be integrated in therapeutic measures; preferentially the influence of interventricular mechanics. Despite of recent developments of specific drug therapies, heart failure is associated with a high rate of morbidity and mortality in children. During the progression of heart failure, pulmonary vascular disease is the consequence or the reason for further failing. Clinical symptoms are associated with congestion and low cardiac output at rest or exercise. Improved understanding of the pathophysiological mechanisms particularly of ventricular failure has resulted in the development of innovative therapies that target atrial/ventricular/arterial interactions. Recent advances in interventional and surgical approaches provide promising new strategies to deal with right and left ventricular deterioration. These techniques may delay listing for heart and (heart-) lung transplantation or even make redundant in individual cases. The beneficial effects of these ventricular interaction strategies are mainly based on the mechanics of the interventricular septum and improvement of systolic and diastolic ventricular performance.
\end{abstract}

Keywords: Pediatric heart failure; pulmonary hypertension (PH); Potts-shunt; dilative cardiomyopathy; pulmonary banding

Submitted Mar 11, 2020. Accepted for publication Apr 15, 2020.

doi: $10.21037 / \mathrm{cdt}-20-347$

View this article at: http://dx.doi.org/10.21037/cdt-20-347

\section{Introduction}

Ventriculo-ventricular interaction (VVI) plays a pivotal role balancing cardiovascular function during health and disease $(1,2)$. The endowment of the heart should be considered as an entity; not at least, under therapeutic aspects (3). Both sides of the heart are inextricably linked through a common septum, myofibers and pericardial space (4). Left ventricular (LV) contraction contributes more than $50 \%$ of right ventricular (RV) work (5). Adverse effects of ventricular- ventricular $(\mathrm{V}-\mathrm{V})$ interactions in heart failure seems to be still incompletely understood or may be only too less taken into account. Consequently, the heart interaction was currently only insufficiently been harnessed for therapeutic benefit.

However, pediatric cardiologists and cardiac surgeons dealing with congenital heart defects (CHDs) have the chance to translate their knowledge in generalized therapeutic concepts. Innate right-left heart interactions in 
CHDs as in congenital corrected transposition of the great arteries (ccTGA) or neonates born with hypoplastic left heart syndrome (HLHS) and complex (HLHC) taught us the meaning of pressure-related VVI and the persistence of intra- and extracardiac communications. A borderline subsystemic ventricle generates a sufficient systemic cardiac output (CO) and oxygen delivery, if all cardiac structures are integrated and cardio-vascular communications guarantee a balanced pulmonary and systemic circulation. Regarding mechanical interactions as well age and disease related cardiac growth and repair potentials $(6,7)$, even univentricular hearts or hearts with a hypoplastic left- or right-side should be considered as a whole.

Therefore, derived from pathophysiologic based therapeutic measures of newborns with borderline left heart structures, newborns with persistent pulmonary hypertension $(\mathrm{PH})$ or patients with an Eisenmengerhemodynamic and those with innate systemic right ventricle, surgical- and catheter-based techniques are able to extend the arsenal of palliative and for some curative treatment.

\section{Neonates with a borderline left heart}

Patients born with a borderline left ventricle (BLV) survive despite or because of persistence of pulmonary hypertension (PPHN) with supra-systemic pulmonary vascular resistance (Rp), but only under the prerequisite of a physiological (fetal) cardio-vascular communications, i.e., open arterial duct. By definition, a significant BLV is unable to generate an adequate systemic CO $(8,9)$. Therefore, newborns with a borderline subaortic ventricle need a support by the dominant subpulmonary ventricle dividing pulmonary blood flow for oxygen up-take and systemic oxygen delivery through a still open arterial duct (PDA). Postnatal adaption of the pulmonary circulation to a low-pressure system is prolonged by the persistence of a restrictive atrial septum defect ( $\mathrm{rASD}$ ). A restrictive atrial communication guarantees a combined postcapillary pulmonary hypertension $(\mathrm{CpcPH})$ and by this, a rightto-left shunt across the open duct. Furthermore, an increased LV preload supports the growth of the subaortic hypoplastic ventricle; however, depending on the amount of achieved blood flow within the BLV (10).

Based on dealing with a neonatal borderline left heart utilizing a hybrid approach consisting of duct stenting, bilateral pulmonary banding and if possible, with a restrictive atrial communication (11-13), we learnt, the prerequisites of a biventricular repair. These are a balanced pulmonary-to-systemic blood flow with an adequate LV preload and a reasonable right-left shunt through the arterial duct.

Growth and functional improvement of the left ventricle is recognizable by an increased acquisition of the systemic $\mathrm{CO}$ by the grown left ventricle. In case of a dominant leftto-right ductal shunt, the aimed biventricular repair has to be performed or if still not suitable, the pulmonary artery branches need to be (re-)banded for avoiding a pulmonary run-off.

Likewise, a non-restrictive atrial communication impedes BLV growth, and might be associated with unstable hemodynamics, if the pulmonary artery branches are insufficiently banded. In such a case, down-sizing of the atrial communication is favored in comparison to intensifying pulmonary branch bandings; additionally, extreme limiting the pulmonary vein flow does not improve BLV growth.

\section{Postnatal PH and Eisenmenger syndrome (ES)}

PPHN of the newborn is a well-known neonatal disease, which is usually a transient phenomenon caused by a delayed postnatal pulmonary adaption. In the majority, PPHN is a self-healing process; independent, whether treatment with pulmonary arterial hypertension (PAH)targeting drugs becomes necessary. However, there is one major difference to the PAH in older children and adults. Postnatally, an atrial communication persists in form of a right-left-shunting patent foramen ovale (PFO) as well as a PDA. However, PPHN with a severe and drugresistant supra-systemic $\mathrm{Rp}$ and an unbalanced ventricular compliance to the disadvantage of the right ventricle, two right-left shunting communications are associated to severe hypoxemia. In doubt, the atrial communication is preferentially closed.

Based on the physiopathology of PPHN and patients with ES, we learnt that "back to the fetal circulation" might be an attractive therapeutic strategy and a realistic option treating advanced $\mathrm{PAH}$ and selected patients with $\mathrm{CpcPH}$. ES represents the most advanced form of $\mathrm{PAH}$ in patients with CHDs. ES is defined as a usually untreated CHD with an intra- or extracardiac communication [ventricular septum defect (VSD), PDA, atrial septum defect (ASD)], which leads or is associated to $\mathrm{PH}$, reversal of shunt flow and consecutive cyanosis. A previous left-to-right shunt has converted into a right-to-left shunt secondary to 
elevated pulmonary arterial pressures (PAPs) and associated pulmonary vascular disease.

Considering the final step of drug-resistant $\mathrm{PAH}$, it became obvious that creation of a right-left shunting communication [reverse Potts-shunt (rPotts)] could be an additional therapeutic option prior to a lung transplantation (14). In patients with "end-stage" heart failure and $\mathrm{CpcPH}$, creation of a restrictive, left-right shunting ASD together with a rPotts has also been shown to be an alternative to a heartlung transplantation (15).

\section{Innate defined systemic right ventricle}

Patients with a congenital corrected transposition (ccTGA, atrio-ventricular, ventriculo-arterial discordance) and transposition of the great arteries (d-TGA, atrial-ventricular concordance and ventriculo-arterial discordance) benefit from remaining high pressure within the subpulmonary positioned left ventricle as long as the $\mathrm{RV}$ is preserved as a systemic ventricle. A balanced innate or acquired equalized interventricular pressure ratio reduces the risk of heart failure (16). In case of an unloaded subpulmonary left ventricle, pulmonary arterial banding $(\mathrm{PAB})$ is utilized for re-training of the ventricle as a procedure of sine qua non prior to a surgical double switch, but even as a long-term palliative measure (17). Furthermore, PAB is also used in infants and young children with ccTGA as a "prophylactic" tool preventing loss of cardiac muscular mass by unloading of the LV during infancy (18). Using this measure in advance, both options remain open: a surgical double switch procedure or a long-term palliation by diminishing the risk of $\mathrm{RV}$ failure, last is best recognizable by the degree of tricuspid valve regurgitation. Tricuspid (systemic atrioventricular valve) valvular regurgitation was shown strongly associated with RV (anatomical right ventricle connected to aorta in ccTGA) dysfunction and congestive heart failure (19).

\section{New developments in surgical/interventional treatment}

The rationale for in part novel surgical/interventional strategies in term of creating a restrictive atrial communication, right-left shunt between the pulmonary artery and descending aortic arch (rPotts) as well as pulmonary bands in LV dilated cardiomyopathy (LV-DCM) is guided by clinical improvement and in selected cases in term of a functional recovery.

\section{Restrictive atrial communication (rASD)}

Atrial septostomy (AS) is an interventional technique, which has been introduced as so-called Rashkind procedure long time ago. Instead of generating an uncontrolled atrial septum defect resulting in deterioration of clinical status, the management of patients with advanced PAH (20-24) or $\mathrm{CpcPH}$ (25-28), includes creation of a well-defined atrial communication with a restrictive pathophysiology. A significant restriction is defined by a residual pressure gradient across such a communication or by a hole-septum ratio of less than $20 \%(29,30)$. The technique can be based on a surgically punched patch or by transcatheter techniques utilizing Brockenbrough transseptal needle puncture followed by gradual balloon dilatation (30) or device placement with a defined hole $(26,27)$. Children with a PAH-related syncope usually have low right atrial pressure (RAP) at rest, but only suddenly increasing pressures during pulmonary hypertensive crisis with an acute low $\mathrm{CO}$ (31). The PH-crisis is characterized by a strong, welltrained right ventricle with a competent tricuspid valve, which has intermittently to act against an extremely high pulmonary arterial resistance (Rp). A limited blood flow through the lungs with consecutive acute reduction of $\mathrm{LV}$ preload are frequently associated with clinical symptoms of "epileptic-seizure-like" convulsions. These patients need to be differentiated from patients with chronic low $\mathrm{CO}$ and systemic vein congestion with increased RAP. Creating of an interatrial communication in case of a chronically increased RAP, a right-to-left shunt will occur already at rest to a decompression of the RA and RV accompanied by increased $L V$ preload and thus, turning physiology into an ASD-like ES. Despite lower arterial oxygen saturation, systemic oxygen transport will increase due to increased CO (22). Creation of a rASD in patients with high RAP $(>18 \mathrm{mmHg}$ ) have to be done with caution: in these patients a 4-mm communication is sufficient to reduce the RAP significantly without inducing a too severe hypoxemia. Considering our institutional experience, a generated rASD only based by gradual balloon dilatation has a significant spontaneous closure or re-intervention rate of $10 \%$ and $30 \%$, respectively. However, the procedure can be repeated safely; stent devices keeping the communication open were also successfully used $(22,31)$. Due to the lack of randomized controlled trials, the role of AS in $\mathrm{PH}$ is still unclear although it represents an additional promising and useful treatment strategy in selected cases, when conducted by an experienced interventionalist. Generating a restrictive 


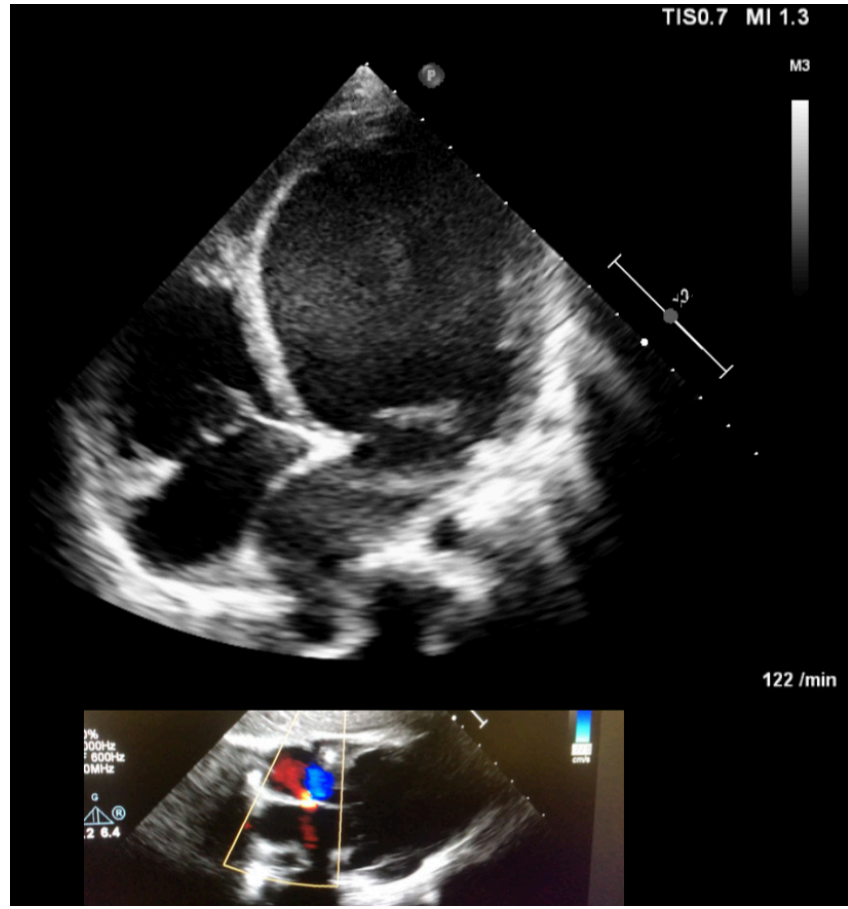

Figure 1 Echocardiography in four chamber view is shown of an infant with dilated cardiomyopathy prior to creation of a restrictive atrial communication (upper part); seen is a dilated left ventricle and left atrium, the left atrial congestion is further recognizable by the shifted atrial septum to the right; the right ventricle is even slightly dilated corresponding with a postcapillary induced pulmonary hypertension. The lower part demonstrates a restrictive atrial communication by color Doppler.

ASD should be considered in patients with advanced NYHA class III and IV or recurrent syncope and chronic low CO despite combined medical therapy as well as a palliative bridge to transplant, increasing the chance for survival while waiting for a donor organ (25).

Patients with left-heart related $\mathrm{CpcPH}$, but even isolated postcapillary $\mathrm{PH}(\mathrm{IpcPH})$, may also benefit from restrictive atrial communication by unloading a congestive or hypertensive left atrium (LA) (Figure 1). Congestive LA as well as pulmonary veins can be effectively relieved and the diuretic treatment reduced or weaned $(30,32)$. Creation of rASD in patients with left atrial hypertension, but not necessarily associated pulmonary congestion at rest despite extreme left atrial pressures (LAPs) in some, is even an effective tool for palliating patients with a significant restrictive LV physiology particularly restrictive cardiomyopathy. A restrictive atrial communication improves exercise capacity and the incidence of atrial tachyarrhythmias by reducing LAP from an extreme to moderate increased pressure level. Because of the atrioventricular coupling, a diminished LA hypertension also decreases the extrinsic part of the increased LV enddiastolic pressure. According to our institutional experience $(28,31,32)$, the decision for cardiac (HTx) or heart-lung transplantation (HLTx) in patients with a NYHA functional class IV and associated $\mathrm{CpcPH}$, should therefore not be considered before a rASD is created. Independent of the systolic pulmonary artery pressure and the calculated mean pressure, the decision for a HTx instead a HLTx can be best made by considering the diastolic pressure gradient (DPG; PAP-diastolic - LAP); a residual DPG of less than $7 \mathrm{mmHg}$ in adults and $12 \mathrm{mmHg}$ in children guide the decision for HTx. Additionally, acute vascular testing of the precapillary component of the $\mathrm{CpcPH}$ makes less sense without a rASD.

According to our current experience with advanced heart failure, a restrictive ASD palliates congestive symptoms of right or left heart disease and reduces the risk of PAHassociated syncope. Meanwhile, a rASD can be created with low-risk, and almost no mortality from infancy to advanced adulthood. The efficacy of a generated rASD is demonstrable by an immediate, but also long-lasting improvement of the clinical functional class. The technique of gradual balloon dilatation of the atrial septum without a defined device fenestration requires repetitive interventions; in our case series, this was applied to about $30 \%$ of treated patients (30). The majority of these patients had heart failure with preserved ejection fraction; a smaller group was treated because of HF with reduced (HFrEF) or because of $\mathrm{PAH}$-associated syncope or manifest right heart congestion.

\section{rPotts}

Considering that the left and right heart works in collaboration, the impact of an arterial communication with generating a right to left shunt-rPotts-has been reported as a novel surgical approach for palliating children with supra-systemic idiopathic PAH (33). The rPotts was considered as a reasonable alternative to lung transplantation (14). The surgical procedure implies the construction of a connection between the left pulmonary artery (LPA) and the descending aorta (DAO) allowing a right-to-left shunt like in a patient with open duct-related ES. In general, a right to-left shunt at the arterial level seems to have advantages comparing a restrictive atrial communication. The rPotts physiopathology provides high 
oxygen saturated blood for the coronary arteries and the central nervous system and only causes desaturation of the lower body (34). In addition, the risk of fatal paradoxical embolisms may be lower compared to a connection on the atrial level. A further benefit arises from its effect on hemodynamics: Relief of RV pressure overload with a subsequent reduction in shifting of the interventricular septum to the left ventricle improves systolic and diastolic $\mathrm{LV}$ performance (35); the diameter of the interarterial communication has to be chosen in order to balance both, a sufficient pulmonary blood flow through the lung for filling the LA guaranteeing a sufficient amount of oxygenated blood, and for supporting the systemic $\mathrm{CO}$ at rest and exercise. Practically, the connection between the pulmonary artery and the DAO can be achieved surgically either by a direct side-by-side anastomosis or by using a synthetic graft tube/prothesis $(15,33)$ or by transcatheter techniques (36). The size of the interatrial communication depends on the pathophysiological condition, the type of connection, but also on the diameter size of the DAO. Several modifications of the procedural strategy have been recently published with the goal to reduce perioperative morbidity and mortality due to open chest surgery. These are mainly based on diverse interventional approaches from resuscitating even a native, surgically or device closed arterial duct (35) by direct high-frequency perforation followed by subsequent covered-stent placement; best, at the small target area where the both vessels (DAO and LPA) are connecting (36). The needle technique, as first described by the Boston group (37), has been abandoned because of safety reasons. Whenever possible, the procedure of duct resuscitating followed by stenting is the method of choice, in consideration of the pediatric cardiologist' experience with complex CHDs and duct-dependent systemic circulation (35). Therefore, it is worth searching carefully for even a tiny duct or a duct ampulla in all patients with supra-systemic $\mathrm{PH}$, which could be used for an interventional creation of an interarterial communication. Further developments of the Potts procedure were the implementation of a unidirectional valve within the Potts anastomosis. Currently it is performed surgically by utilizing a valved conduit (38). Alternatively, even a Melody-valve within a surgically performed Pottsshunt has been used (39) (Figure 2A,B). Placement of a valved conduit allows to perform a reverse Potts-physiology also for patients with sub- or isosystemic pulmonary artery pressure levels, who exhibit supra-systemic pressures during exercise (36) or in patients in whom bidirectional shunting occurs after decompression of the RV.
A rPotts is even a reasonable option in patients with a severe PH caused by left heart disease (15). The first, and meanwhile almost since 8 years palliated adult patient has still a clinical adequate condition with NYHA functional class II.

Several patients with variable complex congenital and acquired heart diseases received meanwhile such an arterial right-left shunt in part with a valved conduit, and several with an additional restrictive left-to-right shunt at the atrial level.

\section{Pulmonary artery banding (PAB) in LV-DCM}

DCM is still a leading cause of mortality in children. Our hypothesis, that $\mathrm{PAB}$ improves $\mathrm{LV}$ failure, in particular of infants and young children with DCM also with the option of functional regeneration was meanwhile confirmed worldwide, in more than 100 treated patients on the concept of a "responder phenotype" (40,41).

The majority of infants with DCM are characterized by a dysfunctional left ventricle with a preserved RV function. Despite the observation, that drug treatment of pediatric heart failure just changes from a symptom guided to a regeneration favoring therapy (42), in an advanced state of heart failure, drug treatment is not further disease modifying, if disease modification is understood as either halting the progression or reversing the DCM. At such point, DCM continues to be highly debilitating and progressive. "End-stage DCM" is defined in affluent countries by its indication to listing for HTx or by considering the use of an assist device, independently of the cause of DCM whether idiopathic, hereditary or any acquired form. Considering the pathobiology of severe DCM as an imbalance of cardiac destructive and repairing mechanisms, treatment options for DCM particularly in infancy should be based on the potentials of cardiac growth, differentiation, proliferation and consecutively regenerative and repair mechanisms (7,43-45). These mechanisms are inversely proportional to the patient's age, which includes edaphic and circulating cardiac progenitor cells as well. Cardiomyocyte mitosis and cytokinesis are described until adolescent age, but with the highest percentage in infants (43). In summary, there are enormous endogenous potentials for functional recovering a diseased heart in particular in infancy. In addition, heart failure has not only age but also disease related specifics (46). In contrast to heart failure of a right ventricle in sub-aortic position (HLHS), DCM is characterized by quite higher regenerative properties (46). 

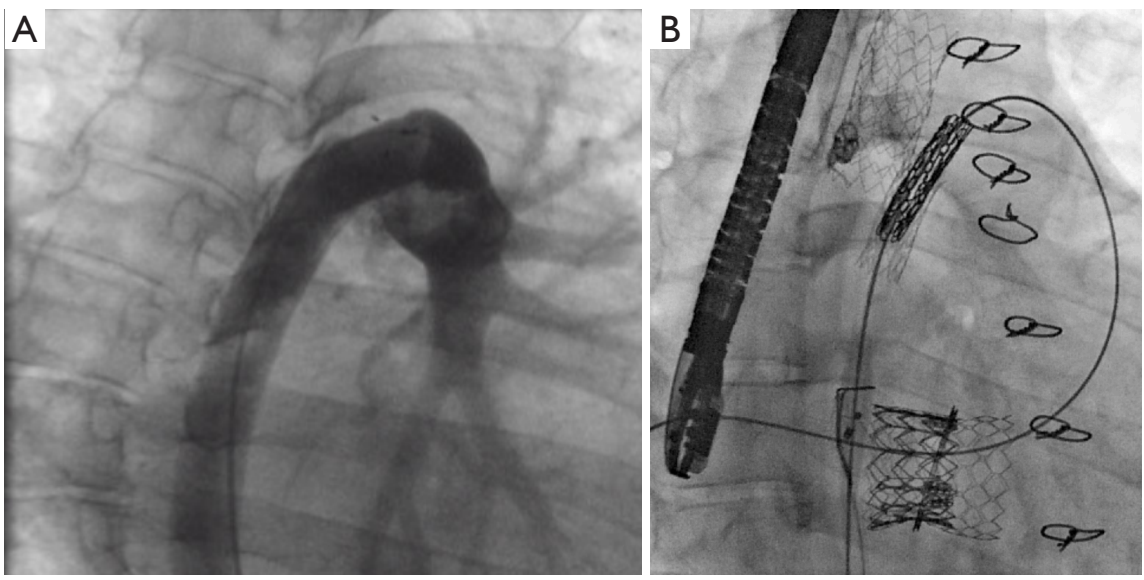

Figure 2 Artificial valved Potts shunt. (A) A surgically performed reverse Potts shunt, which was valved by utilizing a Melody ${ }^{\circledR}$-valve; (B) shows the Melody ${ }^{\circledR}$ ensemble caught by a snare from the arterial side supporting placement of the valve within the Potts-shunt from femoral vein access through an additional re-valved tricuspid valve.

However, despite a dramatic gain in knowledge, it seems to be still a long way to have an exogenous cocktail available to achieve reparation and cardiac regeneration. The introduction of reversible $\mathrm{PAB}(\mathrm{rPAB})$ to the therapeutic arsenal in left heart failure constitutes a paradigm shift, particularly for infants and young children with end-stage DCM. The initial rationale for development of $\mathrm{rPAB}$ was leftward mechanical shift of the interventricular septum; thereby improving LV end-diastolic volume and pressure via improved Frank-Starling effects and filling dynamics, respectively (47). Restored ventricular electromechanical synchrony, increased LV ejection fraction are associated with clinical improvement at rest and during exercise. The interplay of endogenous stimulating and inhibiting mechanisms might be responsible for $\mathrm{PAB}$ induced repair particularly in infants and young children with DCM; the PAB-induced interplay of well-known and unknown molecular parameters seem to work like an epigenetic factor for re-balancing cardiac function and reparation; provided, that the prospectively stressed heart is additionally flanked by heart protecting drugs (48). The surgical risk of $\mathrm{PAB}$ placement in infancy is relatively low. Re-establishing of a high RV pressure is easier to achieve in young age than for an adult heart. In addition, during infancy period, in which patient doubles its body weight, the patient receives the chance to grow into the PAB. In summary, the risk of placing a PAB is relatively low, but the repair potentials enormous. Future studies are needed to delineate further the geometrical, temporal and molecular mechanisms of PABinduced ventricular crosstalk; and to examine their potential modulation through mechanical, electrophysiological and pharmacological interventions.

\section{Acknowledgments}

Funding: None.

\section{Footnote}

Provenance and Peer Review: This article was commissioned by the editorial office, Cardiovascular Diagnosis and Therapy for the series "Pediatric Pulmonary Hypertension". The article has undergone external peer review.

Conflicts of Interest: All authors have completed the ICMJE uniform disclosure form (available at http://dx.doi. org/10.21037/cdt-20-347). The series "Pediatric Pulmonary Hypertension" was commissioned by the editorial office without any funding or sponsorship. CA served as the unpaid Guest Editor of the series. The authors have no other conflicts of interest to declare.

Etbical Statement: The authors are accountable for all aspects of the work in ensuring that questions related to the accuracy or integrity of any part of the work are appropriately investigated and resolved.

Open Access Statement: This is an Open Access article distributed in accordance with the Creative Commons 
Attribution-NonCommercial-NoDerivs 4.0 International License (CC BY-NC-ND 4.0), which permits the noncommercial replication and distribution of the article with the strict proviso that no changes or edits are made and the original work is properly cited (including links to both the formal publication through the relevant DOI and the license). See: https://creativecommons.org/licenses/by-nc-nd/4.0/.

\section{References}

1. Voelkel N, Schranz D. The right ventricle in health and disease. Springer, Heidelberg, 2015.

2. Burns KM, Byrne BJ, Gelb BD, et al. New mechanistic and therapeutic targets for pediatric heart failure: report from a national heart, lung, and blood institute working group. Circulation 2014;130:79-86.

3. Ponikowski P, Voors AA, Anker SD, et al. 2016 ESC Guidelines for the diagnosis and treatment of acute and chronic heart failure: The Task Force for the diagnosis and treatment of acute and chronic heart failure of the European Society of Cardiology (ESC)Developed with the special contribution of the Heart Failure Association (HFA) of the ESC. Eur Heart J 2016;37:2129-200.

4. Sanchez-Quintana D, Anderson RH, Ho SY. Ventricular myoarchitecture in tetralogy of Fallot. Heart 1996;76:280-6.

5. Damiano RJ Jr, La Follette P Jr, Cox JL, et al. Significant left ventricular contribution to right ventricular systolic function. Am J Physiol 1991;261:H1514-24.

6. Amir G, Ma X, Reddy VM, et al. Dynamics of human myocardial progenitor cell populations in the neonatal period. Ann Thorac Surg 2008;86:1311-9.

7. Mishra R, Vijayan K, Colletti EJ, et al. Characterization and functionality of cardiac progenitor cells in congenital heart patients. Circulation 2011;123:364-73.

8. Corno AF. Borderline left ventricle. Eur J Cardiothorac Surg 2005;27:67-73.

9. Ma XJ, Huang GY. Prediction of biventricular repair by echocardiography in borderline ventricle. Chin Med J (Engl) 2019;132:2105-8.

10. Emani SM, McElhinney DB, Tworetzky W, et al. Staged left ventricular recruitment after single-ventricle palliation in patients with borderline left heart hypoplasia. J Am Coll Cardiol 2012;60:1966-74.

11. Michel-Behnke I, Akintuerk H, Marquardt I, et al. Stenting of the ductus arteriosus and banding of the pulmonary arteries: basis for various surgical strategies in newborns with multiple left heart obstructive lesions. Heart 2003;89:645-50.

12. Yerebakan C, Murray J, Valeske K, et al. Long-term results of biventricular repair after initial Giessen hybrid approach for hypoplastic left heart variants. J Thorac Cardiovasc Surg 2015;149:1112-20.

13. Ohye RG, Schranz D, Yves D'Udekem. Current therapy for hypoplasric left Heart Syndrome and related single ventricle variants. Circulation 2016;134:1265-79.

14. Baruteau AE, Belli E, Boudjemline Y, et al. Palliative Potts shunt for the treatment of children with drugrefractory pulmonary arterial hypertension: updated data from the first 24 patients. Eur J Cardiothorac Surg 2015;47:e105-10.

15. Latus H, Apitz C, Schmidt D, et al. Potts shunt and atrial septostomy in pulmonary hypertension caused by left ventricular disease. Ann Thorac Surg 2013;96:317-9.

16. Helsen F, De Meester P, Van Keer J, et al. Pulmonary outflow obstruction protects against heart failure in adults with congenitally corrected transposition of the great arteries. Int J Cardiol 2015;196:1-6.

17. Winlaw DS, McGuirk SP, Balmer C, et al. Intention-totreat analysis of pulmonary artery banding in conditions with a morphological right ventricle in the systemic circulation with a view to anatomic biventricular repair. Circulation 2005;111:405-11.

18. Metton O, Gaudin R, Ou P, et al. Early prophylactic pulmonary artery banding in isolated congenitally corrected transposition of the great arteries. Eur J Cardiothorac Surg 2010;38:728-34.

19. Prieto LR, Hordof AJ, Secic M, et al. Progressive tricuspid valve disease in patients with congenitally corrected transposition of the great arteries. Circulation 1998;98:997-1005.

20. Kerstein D, Levy PS, Hsu DT, et al. Blade balloon atrial septostomy in patients with severe primary pulmonary hypertension. Circulation 1995;91:2028-35.

21. Nihill MR, O'Laughlin MP, Mullins CE. Effects of atrial septostomy in patients with terminal cor pulmonale due to pulmonary vascular disease. Cathet Cardiovasc Diagn 1991;24:166-72.

22. Sandoval J, Gaspar J, Pulido T, et al. Graded balloon dilation atrial septostomy in severe primary pulmonary hypertension. A therapeutic alternative for patients nonresponsive to vasodilator treatment. J Am Coll Cardiol 1998;32:297-304.

23. Micheletti A, Hislop AA, Lammers A, et al. Role of atrial 
septostomy in the treatment of children with pulmonary arterial hypertension. Heart 2006;92:969-72.

24. Keogh AM, Mayer E, Benza RL, et al. Interventional and surgical modalities of treatment in pulmonary hypertension. J Am Coll Cardiol 2009;54:S67-77.

25. Hoffmann R, Altiok E, Reith S, et al. Functional effect of new atrial septal defect after percutaneous mitral valve repair using the MitraClip device. Am J Cardiol 2014;113:1228-33.

26. Del Trigo $M$, Bergeron $S$, Bernier $M$, et al. Unidirectional left-to-right interatrial shunting for treatment of patients with heart failure with reduced ejection fraction: a safety and proof-of-principle cohort study. Lancet 2016;387:1290-7.

27. Hasenfuß G, Hayward C, Burkhoff D, et al. A transcatheter intracardiac shunt device for heart failure with preserved ejection fraction (REDUCE LAP-HF): a multicentre, open-label, single-arm, phase 1 trial. Lancet 2016;387:1298-304.

28. Bauer A, Khalil M, Luedemann M, et al. Creation of a restrictive atrial communication in heart failure with preserved and mid-range ejection fraction: effective palliation of left atrial hypertension and pulmonary congestion. Clin Res Cardiol 2018;107:845-57.

29. Kaye D, Shah SJ, Borlaug BA, et al. Effects of an interatrial shunt on rest and exercise hemodynamics: results of a computer simulation in heart failure. J Card Fail 2014;20:212-21.

30. Bauer A, Esmaeili A, deRosa R, et al. Restrictive atrial communication in right and left heart failure. Transl Pediatr 2019;8:133-9.

31. Bauer A, Khalil M, Schmidt D, et al. Creation of a restrictive atrial communication in pulmonary arterial hypertension (PAH): effective palliation of syncope and end-stage heart failure. Pulm Circ 2018;8:2045894018776518.

32. Bauer A, Khalil M, Schmidt D, et al. Transcatheter Left atrial decompression in patients with Dilated Cardiomyopathy: Bridging to Cardiac Transplantation or Recovery. Cardiol Young 2019;29:355-62.

33. Blanc J, Vouhé P, Bonnet D. Potts shunt in patients with pulmonary hypertension. N Engl J Med 2004;350:623.

34. Delhaas T, Koeken Y, Latus H, et al. Potts shunt to be preferred above atrial septostomy in pediatric pulmonary arterial hypertension patients: a modeling study. Front Physiol 2018;9:1252-5.

35. Latus H, Apitz C, Moysich A, et al. Creation of a functional Potts shunt by stenting the persistent arterial duct in newborns and infants with suprasystemic pulmonary hypertension of various etiologies. J Heart Lung Transplant 2014;33:542-6.

36. Schranz D, Kerst G, Menges T, et al. Transcatheter creation of a reverse Potts shunt in a patient with severe pulmonary arterial hypertension associated with Moyamoya syndrome. EuroIntervention 2015;11:121-3.

37. Esch JJ, Shah PB, Cockrill BA, et al. Transcatheter Potts shunt creation in patients with severe pulmonary arterial hypertension: initial clinical experience. J Heart Lung Transplant 2013;32:381-7.

38. Rosenzweig EB, Ankola A, Krishnan U, et al. A novel unidirectional-valved shunt approach for end-stage pulmonary arterial hypertension: Early experience in adolescents and adults. J Thorac Cardiovasc Surg 2021;161:1438-1446.e2.

39. Recla S, Steinbrenner B, Schreier J, et al. Surgicalinterventional hybrid orchestra consisting of Potts shunt, transcatheter tricuspid valve repair by Edwards-valve in a 26-year-old patient with pulmonary hypertension and right ventricular failure. World J Cardiovasc Dis 2013;3:1-4.

40. Schranz D, Rupp S, Muller M, et al. Pulmonary artery banding in infants and young children with left ventricular dilated cardiomyopathy: A novel therapeutic strategy before heart transplantation. J Heart Lung Transplant 2013;32:475-81.

41. Schranz D, Akintuerk H, Bailey L. Pulmonary artery banding for functional regeneration of end-stage dilated cardiomyopathy in young children: World network report. Circulation 2018;137:1410-2.

42. Schranz D, Voelkel N. Nihilism of chronic heart failure therapy in children and why effective therapy is withheld. Eur J Pediatr 2016;175:445-55.

43. Mollova M, Bersella K, Walsha S, et al. Cardiomyocyte proliferation contributes to heart growth in young humans. Proc Natl Acad Sci U S A 2013;110:1446-51.

44. Liu H, Zhang CH, Ammanamanchi N, et al. Control of cytokinesis by -adrenergic receptors indicates an approach for regulating cardiomyocyte endowment. Sci Transl Med 2019;11:eaaw6419.

45. Yutzey KE. Cytokinesis, Beta-Blockers, and Congenital Heart Disease. New Engl J Med 2020;382:291-3

46. Traister A, Patel R, Huang A, et al. Cardiac regenerative capacity is age- and disease-dependent in childhood heart disease. PLoS One 2018;13:e0200342. 
47. Schranz D, Recla S, Malcic I, et al. Pulmonary Artery Banding in Dilative Cardiomyopathy of Young Children: Review and Protocol based on the current knowledge. Transl Pediatr 2019;8:151-60.

Cite this article as: Schranz D, Akintuerk H, Esmaeili A, Latus H, Apitz C. Heart failure therapy based on interventricular mechanics and cardio-vascular communications. Cardiovasc Diagn Ther 2021;11(4):1080-1088. doi: 10.21037/cdt-20-347
48. Michel-Behnke I, Pavo I, Recla S, et al. Regenerative therapies in young hearts with structural or congenital heart disease. Transl Pediatr 2019;8:140-50. 